\title{
Characteristics of masticatory muscles in children with unilateral posterior crossbite
}

\section{Annicele da Silva Andrade ${ }^{(a)}$ Maria Beatriz Duarte Gavião(b) Gustavo Hauber Gameiro(c) Moara De Rossi(a)}

\footnotetext{
(a) Graduate Student; (b)Professor - Department of Pediatric Dentistry, Piracicaba Dental School, University of Campinas, Piracicaba, São Paulo, Brazil.

(c) Professor, Department of Physiology, Universidade Federal do Rio Grande do Sul - UFRGS, Porto Alegre, Rio Grande do Sul, Brazil.
}

\begin{abstract}
The aim of this study was to detect possible differences in the EMG (electromiography) activity, chewing rate (CR), cycle duration (CD) and preferred chewing side (PCS) between children with and without unilateral posterior crossbite. Thirty-seven children aged from 7 to 10 years were selected from the clinic of the Department of Pediatric Dentistry, Piracicaba Dental School, Brazil, and divided into two groups: unilateral posterior crossbite (UPCB group, $\mathrm{n}=17$ ), and normal occlusion (NOccl group, $\mathrm{n}=20$ ). The PCS was determined using a visual spot-checking method. The EMG activity was recorded during mastication, and two chewing sequences of $20 \mathrm{~s}$ were evaluated to establish each subject's CR (cycles/sec) and CD. UPCB and NOccl groups did not have a PCS. The EMG activity and the cycle characteristics did not differ between the groups. The correlations between CD, CR and EMG activity were statistically significant for the masseter and anterior temporalis muscles only in the NOccl group, in which there was also a significant correlation between the EMG activity of masseter and anterior temporalis. In conclusion, these findings suggest that although children with and without UPCB presented a bilateral masticatory pattern with similar $\mathrm{CR}$ and $\mathrm{CD}$, balanced EMG activity of masseter and anterior temporalis muscles was observed only in the NOccl group. These results indicate that in children, UPCB can alter the coordination of masticatory muscles during mastication.
\end{abstract}

Descriptors: Malocclusion; Electromyography; Mastication.

\section{Introduction}

Posterior crossbite is defined as a malocclusion in the canine, molar and/or premolar regions, characterized by the buccal cusps of the maxillary teeth occluding lingually against the buccal cusps of the corresponding mandibular teeth. ${ }^{1}$ It may develop during eruption of the primary dentition and can involve the permanent dentition at a later stage of development. It may originate from a skeletal or dental malrelationship, or both, and may lead to a mandibular displacement. ${ }^{2}$

Some studies in children and adolescents have shown that posterior crossbite has been associated with asymmetrical function of the masticatory muscles, ${ }^{3-5}$ signs and symptoms of temporomandibular disorders (TMD), such as pain, headache, and muscle tenderness, ${ }^{6,7}$ which may relate to the masticatory muscle performance. ${ }^{4,8}$ Various techniques have
Received for publication on Mar 25, 2010 Accepted for publication on Apr 29, 2010

\author{
Corresponding author: \\ Av. Limeira, 901 \\ CEP: 13414-903 \\ E-mail:mbgaviao@fop.unicamp.br
}


been used to monitor mastication. ${ }^{9}$ Among these techniques, electromyography (EMG), the measurement of the electrical activity of muscles, has found wide application. ${ }^{10}$ EMG has been used to identify differences in chewing patterns between individuals, and to classify them into groups according to their chewing efficiency. ${ }^{11}$

According to Planas ${ }^{12}$ (1997), the crossbite side presents a greater number of occlusal contacts in function, being the preferred chewing side. However, these characteristics were not confirmed by other studies. ${ }^{9,13}$ Chewing side preference was defined by Christensen and Radue ${ }^{14}$ (1985) as: "when mastication is performed consistently or predominantly on the right or left side of the dentition". Considering that masticatory function during growth has a biological impact on the growing structures, a unilateral mastication may lead to asymmetric anatomical structures (bones, temporomandibular joint, muscles, and teeth) on completion of growth. ${ }^{12,15}$ Thus, understanding whether and how posterior crossbite malocclusion influences the preferred chewing side and EMG activity of masticatory muscles would be particularly appropriate.

This study was designed to detect whether there is any difference in the EMG activity during mastication, chewing rate, cycle duration and preferred chewing side between children with and without unilateral posterior crossbite.

\section{Material and Methods}

A cross-sectional study design was used with subjects recruited as a convenience sample of 37 children aged 7-10 years, who were to start dental treatment at the Department of Pediatric Dentistry, Piracicaba Dental School, University of Campinas, Piracicaba, SP, Brazil. The Research Ethics Committee of the Dental School approved the project (Protocol Nos. 020/2006 and 023/2006).

The children were divided into two groups: children with unilateral posterior crossbite (UPCB group,) consisting of 17 subjects aged from 7 to 10 years $(8.65 \pm 1.23)$; from these, 12 subjects had unilateral crossbite on the left side, five on the right side. The control group consisted of 20 children with normal occlusion (NOccl group) (mean age $8.64 \pm 1.15$ years). The children and their parents or guardians received an oral and written explanation about our aims and research methodology. After obtaining the consent of term, we conducted an anamnesis to verify their medical and dental history and oral habits. The exclusion criteria for both groups were the presence of symptoms of craniomandibular dysfunction, major dental reconstructions, previous or current orthodontic treatment, caries, and/or severe gingivitis or missing teeth. Only subjects with unilateral presentation of posterior crossbite with a functional shift of the mandible toward the crossbite side were selected. Children with crossbite resulting from dental inclination were not considered.

\section{Preferred chewing side}

The preferred chewing side was determined using a modification of the visual spot-checking method described by Christensen and Radue ${ }^{16}$ (1985). Subjects were given a $1.7 \mathrm{~g}$ piece of Trident (Cadbury, Bauru, São Paulo, Brazil) (Sugar Free chewing gum) and were instructed to chew in their habitual manner. After $15 \mathrm{~s}$, they were asked to stop chewing, clench the gum between their teeth and grin broadly so that the position of the chewing gum could be observed and recorded as right or left. This procedure was carried out seven times consecutively. The term "observed preferred chewing side" (OPCS) was used when the child chewed $5 / 7,6 / 7$ or $7 / 7$ times on the same side.

\section{Chewing characteristics}

Two chewing sequences of 20 seconds were recorded, as described above. The average of the number of cycles in these two sequences was then divided by $20 \mathrm{~s}$ to establish each subject's automatic habitual chewing rate (cycle/s). Furthermore, the mean duration of each cycle during the 20 seconds was calculated.

\section{Electromyographic evaluation}

The activities of the right and left masseter and anterior temporal muscles were measured by the EMG System do Brazil Ltda. (São Paulo, SP, Brazil) MCS-V2 Electromyograph, using a differential double electrode, a bandpass filter at 20 to $1,000 \mathrm{~Hz}$, 
and a subsequent amplification of 50 times with a common mode rejection ratio of $130 \mathrm{~dB}$ to $60 \mathrm{~Hz}$. The data were sent to a 14-bit A/D converter and sampled at 2,000 Hz. A differential double electrode was used, with 100 times pre-amplification and two contacts measuring $10.0 \times 1.0 \mathrm{~mm}$, with a distance of $10.0 \mathrm{~mm}$ between them, impedance upwards of $10 \mathrm{G} \Omega$ and a common rejection value of $130 \mathrm{~dB}$ to $60 \mathrm{~Hz}$, crafted in silver and fixed in a resin capsule measuring $40 \times 20 \times 5 \mathrm{~mm}$. During the experiment, the child remained comfortably seated, with a straight back and head oriented in the Frankfort plane parallel to the floor. Both the skin and the electrodes were cleaned with 70 percent GL ethyl alcohol in order to eliminate any residues of grease or pollution, and for the anterior temporalis muscle, the skin was shaved, when necessary.

The electrodes were placed on the masseter and anterior temporalis in the following orientations: masseter - level halfway between the zygomatic arch and the gonial angle, close to the level of the occlusal plane; anterior portion of the temporalis muscle - in front of the anterior border of the hairline. A ground electrode was also used on the right hand to reduce electromagnetic interferences and other acquisition noise. The muscle activity was recorded during two chewing sequences (chewing gum) of 20 seconds and the means of root mean square (RMS) were used. The mean of two measurements was considered. The methodology for signal treatment was in accordance with Merletti ${ }^{17}$ (1999). The children were instructed to chew in their habitual manner.

\section{Statistical analysis}

Comparisons between sides (crossbite side vs. non-crossbite side/UPCB group or right side vs. left side/NOccl group) were performed by the paired t-test. The chewing rate and EMG activity were compared between groups using the unpaired $\mathrm{t}$ test. Fisher's exact test was used to associate the preferred chewing side in the two groups. The relationship between chewing characteristics and EMG activity was evaluated by the appropriate Pearson's and Spearman coefficient tests. The level of significance was set at $\alpha=0.05$.

\section{Results}

Table 1 shows the sample distribution, the total crossbite group and control group in relation to preferred chewing side. There was no statistical difference between groups.

Graph 1 shows the comparison between sides in the UPCB and NOccl groups. There were no significant differences between the crossbite side and the normal one in the UPCB group, neither between the right and left sides in the NOccl group. $(\mathrm{p}>0.05)$.

Since there were no differences between sides, the mean EMG values of the right and left masseter and anterior temporalis were considered for comparisons between groups. Graph 2 shows the respective values. There were no significant differences between groups $(\mathrm{p}>0.05)$.

Graph 3 shows the chewing cycle characteristics for UPCB and NOccl groups, in which no significant differences could be observed $(\mathrm{p}>0.05)$.

Table 1 - Sample distribution in relation to preferred chewing side in children with UPCB and NOccl groups.

\begin{tabular}{c|c|c}
\hline & $\begin{array}{c}\text { UPCB group } \\
12 \text { left side/5 right side }\end{array}$ & NOccl group \\
\hline Left & $2 / 0$ & 4 \\
\hline Right & $3 / 1$ & 7 \\
\hline Bilateral & $7 / 4$ & 9 \\
\hline Total & 17 & 20 \\
\hline
\end{tabular}

(Fisher's exact test)
Table 2 - Pearson Correlation Matrix between the EMG of the masseter and temporalis during mastication, and chewing characteristics (chewing rate and cycle duration) obtained in the UPCB and NOccl groups.

\begin{tabular}{c|c|c|c|c|c|c}
\hline \multirow{2}{*}{ Group } & \multicolumn{2}{|c|}{ Chewing rate } & \multicolumn{2}{c|}{ Cycle duration } & \multicolumn{2}{c}{ Masseter } \\
\cline { 2 - 7 } & UPCB & NOcd & UPCB & NOcd & UPCB & NOcd \\
\hline Cycle duration & $-0.99^{* *}$ & $-0.99^{* *}$ & - & - & - & - \\
\hline Masseter & 0.16 & $0.52^{*}$ & -0.11 & $-0.51^{*}$ & - & - \\
\hline Anterior temporalis & 0.30 & $0.44^{*}$ & -0.26 & $-0.44^{*}$ & 0.13 & $0.79^{* *}$ \\
\hline${ }^{*} p<0.05 ;{ }^{* *} p 0.001$.
\end{tabular}




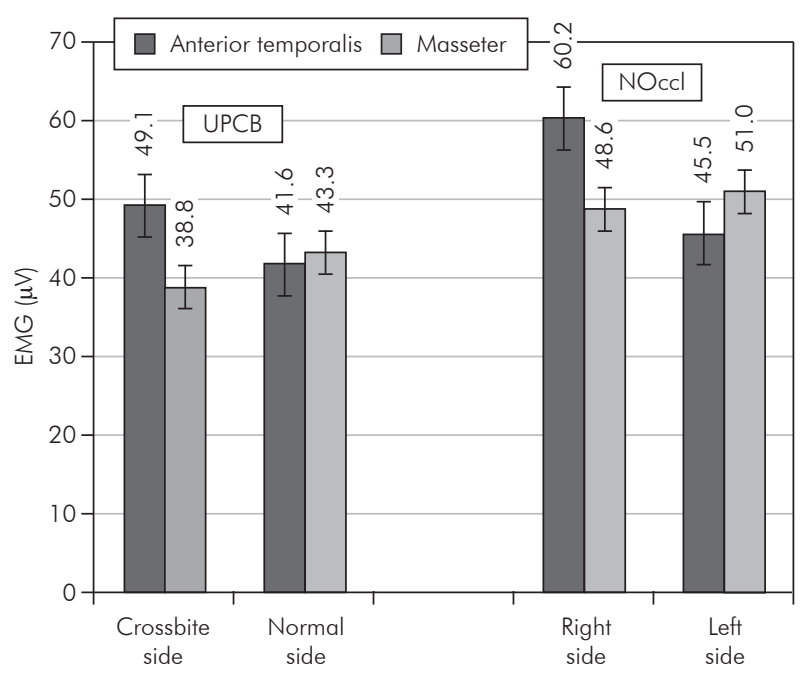

Graph 1 - EMG data $(\mu \mathrm{V})$ from each masticatory muscle during chewing gum (20 s) in children with and without posterior crossbite. Data are plotted as mean \pm SEM ( $p>0.05$, paired t-tests).

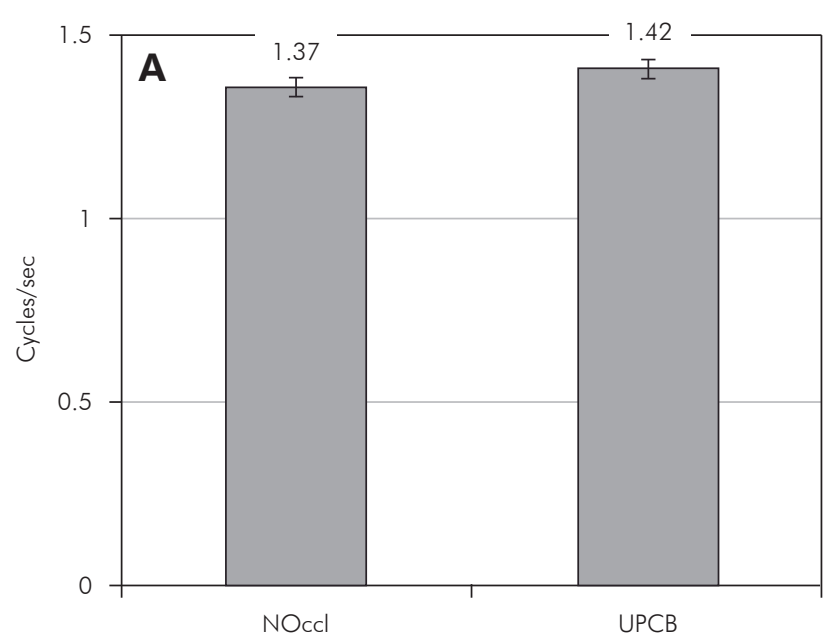

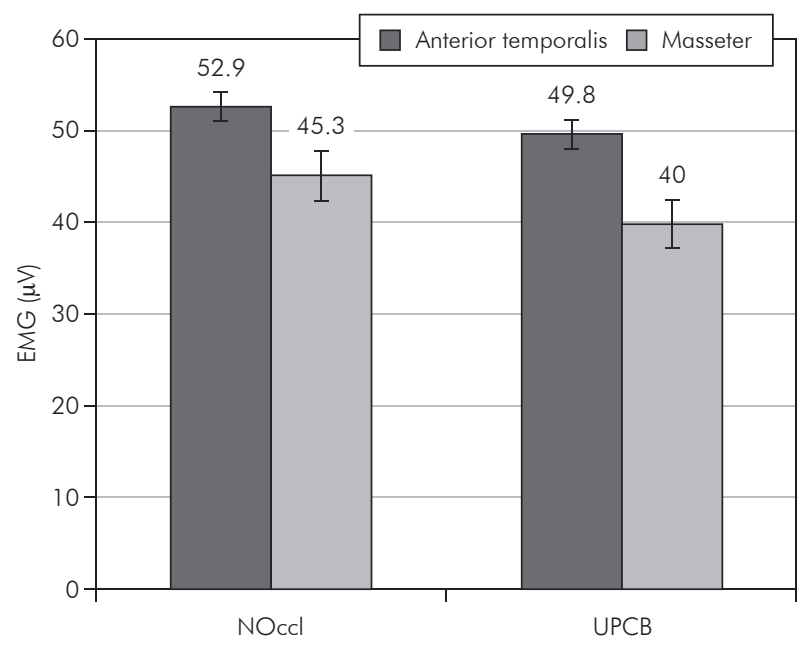

Graph 2 - EMG data $(\mu \mathrm{V})$ of chewing during 20 s. Data are plotted as mean \pm SEM ( $p>0.05$, unpaired t-tests).

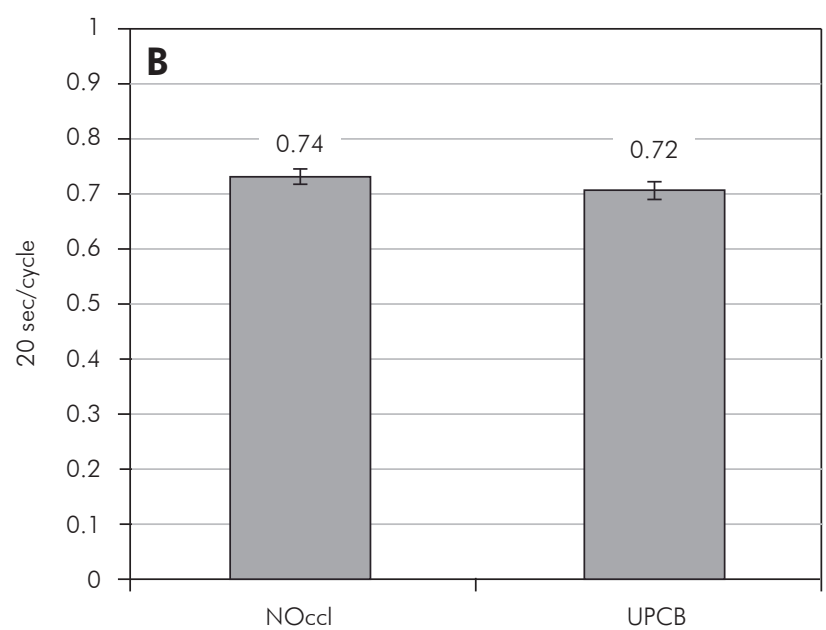

(A) Chewing rate (cycles/s); (B) cycle duration (s). Data Graph 3 - Chewing cycle characteristics for UPCB and NO
are plotted as mean \pm S.E.M ( $>0.05$, unpaired t-tests).

Table 2 reports the correlation between chewing characteristics and EMG activity during chewing in the UPCB group and in the NOccl group. A significant correlation was observed between chewing rate and cycle duration, in both the UPCB and NOccl groups. For the masseter, the correlation between cycle duration and EMG activity in the NOccl group was negative, moderate and significant. Conversely, the correlation between chewing rate and EMG activity of masseter was positive, moderate and significant. As regards the anterior temporalis muscle, the correlations exhibited the same pattern observed in the masseter. Therefore, the EMG activity of the masticatory muscles showed significant correlations with chewing characteristics only in the NOccl group. Moreover, the correlation between the EMG activities of masseter and anterior temporalis was strong and statistically significant only in the NOccl group.

\section{Discussion}

In the present study, using the visual spot-check- 
ing method, it was observed that most of the children with unilateral posterior crossbite showed a bilateral pattern of mastication, without a preferred side, in agreement with previous findings. ${ }^{10,14,18,19}$ There were no significant differences regarding the preferred chewing side between UPCB and NOccl groups (Table 1). These findings could be justified by the fact that chewing is considered an event determined at two levels, an individual central chewing pattern generator, and peripheral events inducing chewing adaptations. ${ }^{20}$ Establishment of the individual central chewing pattern begins with tooth eruption, and is well established in a child with a complete deciduous dentition. ${ }^{21}$ Once the central chewing pattern has been established, it appears to be relatively resistant to change. ${ }^{20}$ Therefore, since the children were evaluated during mixed dentition, they could perhaps persist with the chewing pattern they acquired early.

The above-mentioned comments can be supported by the absence of significant differences in the electrical activity of masseter and anterior temporalis muscles observed between sides in both groups, as well as in inter-groups comparisons (Graphs 1 and 2). These results are in agreement with those obtained by Alarcón et al. ${ }^{13}$ (2000) and Andrade et al. ${ }^{22}$ (2009), in which no significant differences were found between sides in both crossbite and normocclusive subjects. This could mean that during chewing there is a symmetric function of the masticatory muscles, and therefore chewing can be predominantly bilateral, despite the presence of UPCB, as was also previously considered..$^{9,13,18,22}$ Conversely, Egermark-Eriksson et al. ${ }^{6}$ (1990) found that crossbite subjects preferred to chew unilaterally, whereas Ingervall and Thilander ${ }^{18}$ (1975) showed that patients with lateral shift had a lower activity of the anterior and posterior temporalis muscles than normocclusive subjects, but the activity of the masseter muscles was similar in both groups. The discrepancies among the results in different studies may be due to differences between the samples, the location of the measuring points, and the use of different EMG techniques.

Comparisons between the chewing characteristics in children with and without UPCB showed a similar rhythm and cycle duration during mastication (Graph 3), showing that those with UPCB have probably generated adaptive responses to the morphologic alterations, allowing similar masticatory function. Throckmorton et al. ${ }^{20}$ (2001) reported that patients with unilateral posterior crossbite chewed more slowly than did the controls, and after treatment their cycle duration was shortened to equal those of control values. This controversial finding could be due to different methodologies, since they recorded chewing using an intraoral splint attached to each subject's lower teeth, and in the present study the mean EMG activity during chewing was recorded without any intraoral appliance. It is well known that masticatory rhythm is sensitive to sensory input. This peripheral level responds to interferences by slowing or even stopping the chewing cycle, and by lowering the amount of occlusal force used during mastication. ${ }^{23,24}$ However, the chewing cycle duration is much more sensitive to the central pattern generator located in the brain stem, ${ }^{25}$ and the chewing rate is relatively resistant to change. Therefore, the results of the present study suggest that the occlusal interferences associated with crossbite are insufficient to alter the output of the central pattern generator as regards the chewing rate.

Some studies showed that children with a unilateral posterior crossbite exhibit unusual chewing patterns when chewing on the affected side and this is characterized by an increased frequency of reverse sequencing. ${ }^{3,20}$ Ben-Bassat et al. ${ }^{26}$ (1993) and Throckmorton et al. ${ }^{20}$ (2001) reported that successful treatment of a unilateral crossbite with palatal expansion did not eliminate the reverse-sequencing chewing cycles. However, there is evidence that the treatment of posterior crossbite with an orthodontic functional appliance (Function Generating Bite) was able to reduce the prevalence of reverse sequencing chewing cycles in children with this malocclusion. ${ }^{27}$

The current study showed an important finding as regards muscular coordination in children with and without UPCB. In the NOccl group, the electrical activities of masseter and anterior temporalis muscles were strongly correlated, but no cor- 
relations between these muscles were found in the UPCB (Table 2). These results suggest that posterior crossbite negatively affects the performance of masticatory muscles during mastication, leading to a poor muscular coordination in children with this malocclusion. Although the cycle shape has not been evaluated in the present study, the unbalanced muscular activity observed in UPCB could be an important finding, indicating some dysfunction in the mastication process. If the asymmetric masticatory function during growth has a biological impact on the growing structures, which may lead to physical and functional problems, ${ }^{5}$ the present results reinforce the importance of the fact that such asymmetries may be prevented by orthodontic therapy at an early stage in development. ${ }^{28-30}$

\section{References}

1. Bjork A, Krebs A, Solow B. A method for epidemiologic registration of malocclusion. Acta Odontol Scand. 1964 Feb;22(1):27-41.

2. Daskalogiannakis J. Glossary of orthodontic terms. Berlin: Quintessence Publishing Group; 2009. 297 p.

3. Pinto AS, Buschang PH, Throckmorton GS, Chen P. Morphological and positional asymmetries of young children with functional unilateral posterior crossbite. Am J Orthod Dentofacial Orthop. 200 Nov;120(5):513-20.

4. Sonnesen L, Bakke M, Solow B. Bite force in pre-orthodontic children with unilateral crossbite. Eur J Orthod. 2001 Dec;23(6):741-9.

5. Andrade Ada S, Gameiro GH, Derossi M, Gavião MB. Posterior Crossbite and Functional Changes. Angle Orthod. 2009 Mar;79(2):380-6.

6. Egermark-Eriksson I, Carlsson GE, Magnusson T, Thilander B. A longitudinal study of malocclusion in relation to signs and symptoms of craniomandibular disorders in children and adolescents. Eur J Orthod. 1990 Nov;12(4):399-407.

7. Vanderas AP, Papagiannoulis L. Multifactorial analysis of the aetiology of craniomandibular dysfunction in children. Int J Paediatr Dent. 2002 Sep;12(5):336-46.

8. Sonnesen L, Bakke M, Solow B. Malocclusion traits and symptoms and signs of temporomandibular disorders in children with severe malocclusion. Eur J Orthod. 1998 Oct;20(5):54359.

9. Salioni MA, Pellizoni SE, Guimarães AS, Juliano Y, Alonso LG. Functional unilateral posterior crossbite effects on mastication movements using axiography. Angle Orthod. 2005 May;75(3):362-7.

\section{Conclusion}

The present investigation demonstrated that both groups, with and without UPCB did not present a preferred chewing side. The results obtained by EMG evaluation during chewing indicate a bilateral masticatory pattern in both groups, in which the chewing rate and cycle duration were also similar. However, children with UPCB presented poor muscular coordination during mastication.

\section{Acknowledgements}

We are grateful to The National Council for Scientific and Technological Development (CNPq, $\mathrm{BR}$ ) for the scholarship received by the first author and The State of São Paulo Research Foundation (FAPESP, SP, Brazil) (Process 05/03472-4) for financial support.

10. Wendy E, Brown. Method to investigate differences in chewing behaviour in humans. J Texture Stud. 1994;25(1):1-16.

11. Braxton D, Dauchel C, Brown WE. Association between chewing efficiency and mastication patterns for meat, and influence on tenderness perception. Food Qual Prefer. 1996 JulOct;7(3-4):217-23.

12. Planas P. Reabilitação Neuroclusal, $2^{\text {nd }}$ Ed. Rio de Janeiro: Medsi; 1997. 355 p.

13. Alarcón JA, Martín C, Palma JC. Effect of unilateral posterior crossbite on the electromyographic activity of human masticatory muscles. Am J Orthod Dentofacial Orthop. 2000 Sep;118(3):328-41.

14. Christensen LV, Radue JT. Lateral preference in mastication. A feasibility study. J Oral Rehabil. 1985 Sep;12(5):421-7.

15. Liu C, Kaneko S, Soma K. Effects of a mandibular lateral shift on the condyle and mandibular bone in growing rat's. Angle Orthod. 2007 Sep;77(5):787-93.

16. Christensen LV, Radue JT. Lateral preference in mastication: an electromyographic study. J Oral Rehabil. 1985 Fall;12(5):429-34.

17. Merletti R. Standards for reporting EMG data. J Electromyogr Kinesiol. 1999 Feb;9 (1): III-IV.

18. Ingervall B, Thilander B. Activity of temporal and masseter muscles in children with a lateral forced bite. Angle Orthod. 1975 Oct;45(4):249-58.

19. Martín C, Alarcón JA, Palma JC. Kinesiographic study of the mandible in young patients with unilateral posterior crossbite. Am J Orthod Dentofacial Orthop. 2000 Nov;118(5):554-8.

20. Throckmorton GS, Buschang PH, Hayasaki H, Pinto AS. Changes in the masticatory cycle following treatment of poste- 
rior unilateral crossbite in children. Am J Orthod Dentofacial Orthop. 2001Nov;120(5):5521-9.

21. Wickwire NA, Gibbs CH, Jacobson P, Lundeen HC. Chewing patterns in normal children. Angle Orthod. 1981 Jan;51(1):148-60.

22. Andrade AS, Gavião MB, Derossi M, Gameiro GH. Electromyographic activity and thickness of masticatory muscles in children with unilateral posterior crossbite. Clin Anat. 2009 Mar;22(2):200-6.

23. Ingervall B, Carlsson GE. Masticatory muscle activity before and after elimination of balancing side occlusal interference. J Oral Rehab. 1982 May;9(3):183-92.

24. Bakke M, Michler L, Moller E. Occlusal control of mandibular elevator muscles. Scand J Dent Res. 1992 Oct;100(5):28491.

25. Thexton AJ. Mastication and swallowing: an overview. $\mathrm{Br}$ Dent J. 1992 Oct 10;173(6):197-206.

26. Ben-Bassat Y, Yaffe A, Brin I, Freeman J, Ehrlich Y. Functional and morphological-occlusal aspects in children treat- ed for unilateral posterior cross-bite. Eur J Orthod. 1993 Feb;15(1):57-63.

27. Piancino MG, Talpone F, Dalmasso P, Debernardi C, Lewin A, Bracco P. Reverse-sequencing chewing patterns before and after treatment of children with a unilateral posterior crossbite. Eur J Orthod. 2006 Oct;28(5):480-4.

28. Castelo PM, Bonjardim LR, Pereira LJ, Gavião MB. Facial dimensions, bite force and masticatory muscle thickness in preschool children with functional posterior crossbite. Braz Oral Res. 2008 Jan-Mar;22(1):48-54.

29. Lam PH, Sadowsky C, Omerza F. Mandibular asymmetry and condylar position in children with unilateral posterior crossbite. Am J Orthod Dentofacial Orthop. 1999 May;115(5):56975.

30. Gazit-Rappaport T, Bayer A, Gazit E. An innovative orthodontic-prosthetic approach for a patient with dental and skeletal asymmetry. Am J Orthod Dentofacial Orthop. 2003 Feb;123(2):185-91. 